peak plasma insulin value was reached 15 minutes after glucose injection.

These findings lead us to conclude that intravenous administration of hypertonic solutions such as glucose $40 \%$, but probably also radiographic contrast media, may cause a fall of blood pressure in the elderly, probably through direct vasodilatation. Secondly, the endogenous insulin response to glucose $40 \%$ given intravenously elicited no effect on blood pressure in the elderly.

R JANSEN

W HOEFNAGELS

University Hospital Nijmegen,

PO Box 9101,

6500 HB Nijmegen,

The Netherlands

1 Jansen RWMM, Hoefnagels WHL. Influence of oral and intrav . .ous glucose loading on blood pressure in normotensive and hypertensive elderly subjects. Joumal of Hypertension (in press).

2 Jansen RWMM, Penterman BJM, van Lier HJJ, Hoefnagel WHL. Blood pressure reduction after oral glucose loading and its relation to age, blood pressure and insulin. $\mathrm{Am} \mathcal{F} \mathrm{Cardiol}$ (in press).

\section{Health and nutrition of Ethiopian refugees in emergency camps}

SIR,-Dr Paul Shears and colleagues draw attention to the high mortality among Ethiopian refugees arriving in the Sudan in 1985 (1 August, p 314). The mortality remained high despite the relief programme in the area and was observed in a number of camps with differing standards of relief services.

The main determinant of mortality was the extremely poor nutritional state of the population on arrival. Severely malnourished people of all ages may be kept alive for some time by the efforts of relief agencies, but they often fail to improve nutritionally because of impaired gastrointestinal and metabolic function and finally succumb to infection weeks later. Reactivation of infections with refeeding was not specifically recognised but might have contributed to the delayed mortality in that confused environment. ${ }^{12}$

The authors do not regard water supplies as a major problem. As one who was working in the area at that time, I know that in many of the camps the water supply was the weak link in the provision of early services in the emergency. Both the quality and, more importantly, the quantity of water were inadequate.

There was another factor which probably added to the high mortality. Non-governmental agencies appeared at times to be more concerned with interagency rivalry and the pursuit of rigid ideology than the welfare of the refugees. On one occasion three agencies were asked to provide medical services for a large group of new arrivals in very poor condition. None of these agencies wanted to be involved in "curative medicine." As a result, during the first critical weeks, when many of the population were acutely ill, the curative services provided were quite inadequate and many died of treatable conditions. Agencies concerned in disaster relief programmes must make the welfare of the victims their prime concern rather than their own prestige or ideology.

Kim MULHOLLAND

Royal Children's Hespital

Melbourne,

Australia

1 Murray J, Murray A. Suppression of infection by famine and its activation by refeeding - a paradox? Perspectives in Biology and Medicine 1977;20:471-83.

2 Edirisinghe JS. Infection and the malnourished: with specis reference to malaria and malnutrition in the tropics. Ann Trop Paediatr 1986;6:233-7.

\section{Regular Review: Somatostatin}

SIR,-We would like to comment on the statement made by Professors S.R Bloom and J M Polak (1 August, p 288) about the efficacy of somatostatin in controlling variceal haemorrhage. They state that "the initial reports were good but have not been confirmed, and the long acting analogue is of doubtful usefulness in treating either bleeding peptic ulcer or bleeding varices." Though studies of the efficacy of somatostatin in controlling haemorrhage from peptic ulceration have produced conflicting results, this is not the case with bleeding oesophageal varices. Thus control of bleeding was achieved in 47 of the 62 episodes of variceal haemorrhage treated with somatostatin in the three published randomised controlled clinical trials, a success rate of $74 \% .^{1-3}$ Such an outcome compares favourably with that achieved with vasopressin, which in the 13 randomised contro trials reported to date has controlled bleeding in 122 out of $238(51 \%)$ episodes of bleeding. Moreover, no major complications have been associated with the use of somatostatin to contro variceal haemorrhage, in contrast to vasopressin, which, at the dosages used to control variceal haemorrhage, may produce serious, and sometimes fatal, side effects in about $15-25 \%$ of patients. Therefore at present the evidence suggests that somatostatin is safer and more effective than vasopressin for the control of acute variceal haemorrhage.

There is little doubt that injection sclerotherapy is currently the treatment of choice for the control of acute variceal haemorrhage, bleeding being controlled in about $85-95 \%$ of patients presenting for treatment. The facilities for injection sclerotherapy, however, are not always available at the admitting hospital, and there may be no one present with the skill to inject a copiously bleeding varix. Consequently, there is a need for a stop gap treatment that is safe and effective and can be instituted rapidly without the need for special skills. As balloon tamponade of the oesophagus may be associated with a prohibitively high complication rate and requires skilled use, we believe that such circumstances necessitate a safe pharmacological agent to control bleeding. Evidence suggests that somatostatin is effective for this purpose. Clearly, however, further prospective randomised trials are required to confirm the role of somatostatin, and possibly its analogues, in controlling acute variceal haemorrhage.

S A JENKINS J N BAXTER S ELLENBOGEN

University of Liverpool

R SHIELDS

Liverpool L69 3BX

Kravetz D, Bosch J, Teres J, Bruix J, Rimola P, Rodes J. Comparison of intravenous somatostatin and vasopressin infusion in treatment of acute variceal haemorrhage. Hepatology 1984;4:442-4.

2 Jenkins SA, Baxter JN, Corbett W, Devitt P, Ware J, Shields R. A prospective controlled clinical trial comparing somatostatin and vasopressin in controlling acute variceal haemorrhage. BrMed F 1985;290:275-8.

3 Testoni PA, Masci E, Passaretti A, et al. Comparison of somatostatin and cimetidine in the treatment of acute bleeding esophageal varices. Current Therapeutic Research 1986;39. 758-66.

\section{Abuse of fresh frozen plasma}

SIR,-I agree wholeheartedly with Dr Jennifer Jones about the abuse of fresh frozen plasma (1 August, $p$ 287), but she does not discuss its use in the special care baby unit, where it has been recommended for premature infants who are at risk from intraventricular haemorrhage and who commonly have a haemostatic defect which may contribute to their death. ${ }^{1-6}$

Over two years we identified 21 premature infants (gestational age 29 weeks, range 25-32 weeks) with abnormal clotting on the first day of life (international normalised ratio greater than $2 \cdot 0$, kaolin-cephalin clotting time ratio greater than $2 \cdot 0$ ). Fifteen babies with abnormal clotting received fresh frozen plasma in a dose of $10 \mathrm{ml} / \mathrm{kg}$ and had a repeat clotting sample tested within 24 hours. In all the clotting ratios were normal. The mean reduction in international normalised ratio was 0.7 (range $0.2-1.5$ ) and mean reduction in kaolin-cephalin clotting time ratio was 1.6 (range $0 \cdot 6-4 \cdot 5)$.

During the period of study seven babies were found at necropsy to have substantial intraventricular haemorrhage. Of these, two babies with abnormal clotting ratios (international normalised ratio 1.9 and 3.2 , clotting time ratio 6.0 and 6.0) had received fresh frozen plasma while five babies with normal clotting ratios had not received fresh frozen plasma.

Thus, although we are confident that we can correct the haemostatic defect with fresh frozen plasma, we have no evidence that this can save lives.

R V MAJER P J GREEN P WEIR

Haematology Department

St Mary's Hospital,

Portsmouth PO3 6AG

1 Anonymous. Ischaemia and haemorrhage in the premature brain. [Editorial.] Lancet 1984;ii:847-8.

2 Hambleton G, Appleyard WJ. Controlled trial of fresh frozen plasma in asphyxiated low birthweight infants. Arch Dis Child 1973;48:31-5.

3 Setzer ES, Webb IB, Wassenaar JW, Reeder JD, Merhta PS, Eitzman DV. Platelet dysfunction and coagulopathy in intraentricular haemorrhage in the premature infant. $f$ Pediatr 1982;100:599-605.

4 Beverley DW, Chance GW, Inwood MJ, Schaus M, O'Keefe B. Intraventricular haemorrhage and haemostasis defects. Arch Dis Child 1984;59:444-8.

Waltl H, Kurz R, Mitterstieler G, Fodisch HJ, Hohenauer L, Rossler H. Intracranial haemorrhage in low-birth-weight infants and prophylactic administration of coagulation-factor concentrate. Lancet 1973;ii:1284-6.

6 Thomas DB, Burnard ED. Prevention of intraventricular haemorrhage in babies receiving artificial ventilation. Med $\mathcal{J}$ Aust 1973;i:933-6.

Rapid resolution of signs of primary intracerebral haemorrhage in computed tomograms of the brain

SIR,-I cannot agree with the uncritical dismissal by $\operatorname{Dr} M S$ Dennis and colleagues of magnetic resonance imaging in the investigation of stroke $(8$ August, $p$ 379). They are also mistaken in their belief that it is the $T_{2}$ relaxation time which distinguishes subacute haemorrhage from infarction and cite early work which did not compare haemorrhage and infarction but dealt with a small heterogeneous collection of intracranial haemorrhages imaged at different times on a low resolution prototype 0.147 tesla resistive system.

Numerous clinical studies have documented the superiority of magnetic resonance imaging over computed tomography in detecting cerebral infarcts. ${ }^{1-3}$ These changes in ischaemic brain are shown earlier on magnetic resonance imaging than computed tomography, ${ }^{4}$ because small increases in tissue water insufficient to change $x$ ray attenuation coefficients are shown by a prolongation of the magnetic relaxation time. This gives a typical hyperintense signal on a $T_{2}$ weighted image and an isointense or hypointense signal on a $T_{1}$ weighted image.

Although more noticeable on high field than on 